\title{
Sites Regression GGE Biplot Analysis of Haricot Bean (Phaseolus vulgaris L.) Genotypes in three Contrasting Environments
}

\author{
Tamene T. Tolessa*, Tadese S. Gela \\ Ethiopian Institute of Agricultural Research, Kulumsa Agricultural Research Center, Asella, Ethiopia \\ *Corresponding author: tt.tolassa@gmail.com
}

Received July 31, 2014; Revised September 09, 2014; Accepted September 25, 2014

\begin{abstract}
Fourteen haricot bean genotypes were evaluated at three contrasting environments in Ethiopia during 2007-2009 main cropping seasons. The objective of the study was to determine the magnitude and pattern of $\mathrm{G} \times \mathrm{E}$ interaction and yield stability, and to determine the best performing varieties for selection environments. The study was conducted using a randomized complete block design with 4 replications. $G \times$ E interaction and yield stability were estimated using the sites regression genotype plus $\mathrm{G} \times \mathrm{E}$ interaction biplot. Pooled analysis of variance for grain yield showed significant $(\mathrm{p} \leq 0.001)$ differences among the genotypes, environments and for $\mathrm{G} \times \mathrm{E}$ interaction effects. This indicated that the genotypes differentially responded to the changes in the test environments or the test environments differentially discriminated the genotypes or both. Environment accounted for 50.2\% of the total yield variation, genotype for $29.1 \%$ and $\mathrm{G} \times \mathrm{E}$ interaction for $18.3 \%$, indicating the necessity for testing haricot bean varieties at multi-locations and over years. The first two multiplicative component terms sum of squares of the GGE biplot explained $85.76 \%$ of the interaction sum of squares. There were no single genotypes that showed generally superior performance across all the test environments but genotype 213-FOT-15 followed by other three better performing genotypes including 551-SEQ-1024, BAYOMADERO-75 and ZEBRA, were ranked first in 78\% and $67 \%$ of the nine test environments, respectively and identified as stable based on GGE analysis. Generally, the application of sites regression GGE biplots facilitated the visual comparison and identification of superior genotypes, thereby supporting decisions on haricot bean variety selection and recommendation in different environments.
\end{abstract}

Keywords: $G \times E$ interaction, haricot bean, sites regression GGE biplot, yield stability

Cite This Article: Tamene T. Tolessa, and Tadese S. Gela, "Sites Regression GGE Biplot Analysis of Haricot Bean (Phaseolus vulgaris L.) Genotypes in three Contrasting Environments.” World Journal of Agricultural Research, vol. 2, no. 5 (2014): 228-236. doi: 10.12691/wjar-2-5-5.

\section{Introduction}

Haricot bean, also known as common bean (Phaseolus vulgaris L.) is among the major pulses grown in the lowland to mid-altitude sub-humid agro-ecologies of Ethiopia [27]. In contrast to most of the largest world haricot bean producing countries, in the recent years, there was an increasing trend in both haricot-bean area cultivation and annual production in Ethiopia [28]. It is the second most important food legume next to faba bean. Currently, haricot bean occupies $19.7 \%$ of the total area cultivated for pulses with $16.8 \%$ of the total annual pulses production in the country [6]. Haricot bean is a crop of rich protein and minerals such as iron and zinc in the diet, which has short maturity period of about three months, so as available for family consumption during the period when other crops are immature [27]. In Ethiopian lowland and mid-altitude sub-humid agro-ecologies, haricot bean is a suitable rotation crop with maize, sorghum, and vegetables and should be a component of this farming system to keep sustainable agriculture in the country.
To maintain improved agricultural productivity, the development of varieties with high yielding potential is the ultimate goal of plant breeders in a crop improvement program. In the recent years of haricot bean breeding in Ethiopia, special focuses have been paid to develop varieties with improved grain yield, good seed color and size as well as, resistant to major diseases. In addition to high yielding potential, a successfully developed new cultivar should have a stable performance and broad adaptation over a wide range of environments. However, frequent variation experienced both from season to season and from place to place within a shorter distance is among the most important features of the Ethiopian environmental conditions [11]. In such cases, genotype $\times$ environment $(G \times E)$ interaction effect is expected to be greater [12]. Thus, evaluation of different genotypes in a multi-environment and/or year is not only important to determine high yielding cultivars but also to identify sites that best represent the target environment [34]. However, genotype grown in different environments frequently show significant fluctuations in yield performance and these changes are influenced by the different 
environmental conditions and are referred to as $\mathrm{G} \times \mathrm{E}$ interaction [2].

$\mathrm{G} \times \mathrm{E}$ interaction cannot explained by the genotype main effect $(G)$ and the environment main effect (E) [22] but both $\mathrm{G}$ and GE must considered simultaneously. $\mathrm{G} \times \mathrm{E}$ interaction associated with significant genotypic rank change over environments potentially present limitations on selection and recommendation of varieties for target set of environments [20]; and reduces the genetic progress in plant breeding programs. Therefore, understanding the cause of $\mathrm{G} \times \mathrm{E}$ interaction is used to identify ideal test environments and formulate recommendations for areas of optimal genotype adaptation [33]. On the other hand, if the intended cultivar selection is for a large group of environments, stability and mean yield across all environments are more important than yield for specific environments [21]. Hence, $\mathrm{G} \times \mathrm{E}$ interaction must either exploited by selecting superior genotype for each specific target environment or avoided by selecting widely adapted and stable genotype across wide range of environments [5].

In their investigation of $\mathrm{G} \times \mathrm{E}$ interaction, researchers have proposed and used numerous statistical models for understanding the causes of $\mathrm{G} \times \mathrm{E}$ interaction effects in variety development process [29]. The practical uses of different statistical methods to explain $G \times E$ interaction, and facilitate variety release decision have been extensively reviewed and published elsewhere [7,13,14,19,42]. However, not all of them are always effective enough in analyzing the multi-environment data structure [20,42]. Site regression genotype plus $G \times E$ interaction (GGE) biplot model is among powerful tools for effective analysis and interpretation of multienvironment data structure in breeding programs [23,31]. It is a multiplicative model that combines the two important factors in variety selection (i.e., the main effects of genotypes $(G)$ plus the $G \times E$ interaction $(G E)$ which denoted as (G+GE or GGE) [31,38]. The application of GGE models for explaining $G \times E$ interaction and analyzing the performance of genotypes and test environments have been very frequent among plant breeders in recent years [3,16,39].
Although all aforementioned and several other techniques has been proposed to characterize the stability of yield performance across a wide range of test environments. Previous works that has been reported on haricot bean genotypes performance stability in Ethiopia were either based on multivariate statistics such as AMMI $[1,9]$ or have been used only few regression/parametric approaches $[1,9,25]$. This experiment was therefore, attempted to apply sites regression GGE biplot statistical model for determination of the magnitude and pattern of $G$ $\times \mathrm{E}$ interaction effects and performance stability of grain yield in selected haricot bean genotypes.

\section{Materials and Methods}

\subsection{Testing Sites, Breeding Materials and Experimental Design}

The field experiment was conducted at three contrasting locations including Kulumsa, Dhera and Asassa during 2007-to-2009 main cropping seasons using 14 haricot bean genotypes, year location combination being considered as environment. Kulumsa is a mid-altitude environment receiving enough rainfall with even distribution throughout the cropping season. Dhera is characterized as drought prone lowland environment receiving unpredictable rainfall pattern, while Asassa is a mid-altitude environment with terminal moisture stress. Full description of the 3 test locations and 14 haricot bean genotypes are given in Table 1 and Table 2, respectively.

The treatments were arranged in a randomized complete block design with four replications. The plot size was $6.4 \mathrm{~m}^{2}$ with four rows of $4 \mathrm{~m}$ long and spacing of 40 $\mathrm{cm}$ between rows. Fertilizer at the rate of $18 \mathrm{~kg} \mathrm{~N}$ and 46 $\mathrm{kg} \mathrm{P}_{2} \mathrm{O}_{5}$ in the form of DAP (Diammonium Phosphate) and $100 \mathrm{~kg} \mathrm{ha}^{-1}$ seed rate was used at each test sites. For statistical analysis, yield from net plot area of $3.2 \mathrm{~m}^{2}$ was harvested and converted into $\mathrm{kg} \mathrm{ha}^{-1}$ base at $10 \%$ standard grain moisture content was used.

Table 1. Description of the test locations

\begin{tabular}{|c|c|c|c|c|c|c|c|}
\hline \multirow[t]{2}{*}{ Locations } & \multicolumn{2}{|c|}{ Geographical Position } & \multirow[t]{2}{*}{ Altitude (m.a.s.l.) } & \multirow{2}{*}{$\begin{array}{c}\text { Average } \\
\text { rainfall } \\
(\mathrm{mm})\end{array}$} & \multicolumn{2}{|c|}{$\begin{array}{c}\text { Temperature } \\
\left({ }^{\circ} \mathrm{C}\right)\end{array}$} & \multirow[t]{2}{*}{ Soil type } \\
\hline & Latitude & Longitude & & & Min & Max & \\
\hline Asassa & $07^{\circ} 07^{\prime} 09^{\prime \prime} \mathrm{N}$ & $39^{\circ} 11^{\prime} 58^{\prime \prime} \mathrm{E}$ & 2340 & 620 & 5.8 & 23.6 & Gleysol \\
\hline Kulumsa & $08^{\circ} 01^{\prime} 10^{\prime \prime} \mathrm{N}$ & $39^{\circ} 09^{\prime} 11^{\prime \prime} \mathrm{E}$ & 2200 & 820 & 10.5 & 22.8 & Luvisol \\
\hline Dhera & $08^{\circ} 19^{\prime} 10^{\prime \prime} \mathrm{N}$ & $38^{\circ} 19^{\prime} 13^{\prime \prime} \mathrm{E}$ & 1650 & 596 & 14 & 27.8 & Andosol \\
\hline
\end{tabular}

m.a.s.l. = meters above sea level, $\min =$ minimum, $\max =$ maximum

Table 2. Description of the 14 haricot bean genotypes tested across 3 different environments during 2007-2009 cropping season

\begin{tabular}{cccccc}
\hline No & Genotype & Source & No & Genotype \\
\hline 1 & BAYOMADERO-75 & CIAT/Colombia & 8 & $213-F O T-15$ & Source \\
2 & 551-SEQ-1024 & CIAT/Colombia & 9 & 630 ESLES & CIAT/Colombia \\
3 & GORBANCILION & CIAT/Colombia & 10 & MAM-36 & CIAT/Colombia \\
4 & CARIOCA & CIAT/Colombia & 11 & BM-06-01 & Landrace Collection \\
5 & 720 FOT-49 & CIAT/Colombia & 12 & COLL/06-1 & BM-06-02 \\
6 & 855 POMPADOURG & CIAT/Colombia & 13 & ZEBRA \\
\hline
\end{tabular}

\subsection{Statistical Procedures}

The grain yield data were subjected to General Linear Model (PROC GLM) procedure using SAS version 9.0
[24] to determine the existence of significant difference between the genotypes for grain yield performance at each environment and combined over environment. Error mean squares from each environment were tested for 
homogeneity of variance to ensure the combined analysis across environments was appropriate. Separation of the additive main effect was done using Duncan's Multiple Range Tests (DMRT). A stratified ranking for grain yield based on the technique suggested by [15] was done using the SAS program developed by [19] to determine the "top, middle and lower" third genotypes across the environments. Sites regression GGE biplots were produced using the SAS program following the procedures of [17] as modified by [4].

The following sites regression linear-bilinear model was used for analysis of $\mathrm{G}$ x E interaction:

$$
\bar{y}_{\mathrm{ij} .}=\mu+\delta_{\mathrm{j}}+\sum_{\mathrm{k}=1}^{\mathrm{t}} \lambda_{\mathrm{k}} \alpha_{\mathrm{ik}} \gamma_{\mathrm{jk}}+\bar{\varepsilon}_{\mathrm{ij}} .
$$

where $\bar{y}_{i j}$. is the mean of the $i^{\text {th }}$ genotype in the $j^{\text {th }}$ environments; $\mu$ is the overall mean; $\delta_{j}$ is the site effect; $\lambda_{k}\left(\lambda_{1} \geq \lambda_{2} \geq \cdots \geq \lambda_{t}\right)$ are scaling constants (singular values) that allow the imposition of orthonormality constraints on the singular vectors for genotypes, $\alpha_{i k}=\left(\alpha_{1 k}, \ldots, \alpha_{g k}\right)$ and sites, $\gamma_{j k}=\left(\gamma_{1 k}, \ldots, \gamma_{e k}\right)$, such that $\sum_{\mathrm{i}} \alpha_{i k}^{2}=\sum_{\mathrm{j}} \gamma_{j k}^{2}=1$ and $\sum_{\mathrm{i}} \alpha_{i k} \alpha_{i k^{\prime}}=\sum_{\mathrm{j}} \gamma_{j k} \gamma_{j k^{\prime}}=0$ for $\mathrm{k} \neq \mathrm{k}^{\prime} ; \quad \alpha_{i k}$ and $\gamma_{j k}$ for $\mathrm{k}=1,2,3, \ldots$ are called "primary," "secondary," “tertiary,". . . etc. effects of genotypes and sites, respectively; $\bar{\varepsilon}_{i j}$ is the residual error assumed to be $\operatorname{NID}\left(0, \sigma^{2} / r\right)$ (where $\sigma^{2}$ is the pooled error variance and $r$ is the number of replicates). Least squares estimates of the multiplicative (bilinear) parameters in the $\mathrm{k}^{\text {th }}$ bilinear term are obtained as the $\mathrm{k}^{\text {th }}$ component of the deviations from the additive (linear) part of the model. In the sites regression model, the main effects of cultivars (G) plus the $G \times E$ interaction is absorbed into the bilinear terms.

\subsection{Mean Performance of Genotypes and Environments}

Pooled analysis of variance of grain yield $\left(\mathrm{kg} \mathrm{ha}^{-1}\right)$ of 14 haricot bean genotypes tested in 9 environments indicated that genotypes, environments and $\mathrm{G} \times \mathrm{E}$ interaction were significantly $(\mathrm{p} \leq 0.001)$ different, with coefficient of variability of $24.9 \%$ and coefficient of repeatability $\left(\mathrm{R}^{2}\right)$ being $89 \%$ (Table 3). Environmental effect (E), which accounted for $(50.13 \%)$ of the yield variation was found responsible for the greatest part of the total variation, followed by genotype $(G)$ and $G \times E$ interaction effects explained $29.11 \%$ and $18.28 \%$, respectively. Separate year analysis also revealed that the largest yield variation was accounted by environmental effect than the other source of variations (data not shown). Similar result was reported in northern Ethiopia in bread wheat [18]. The environments average grain yield across genotypes was ranged from as low as $448 \mathrm{~kg} \mathrm{ha}^{-1}$ for E9 to $4298 \mathrm{~kg} \mathrm{ha}^{-1}$ for E7 followed by $2978 \mathrm{~kg} \mathrm{ha}^{-1}$ for E2 (Table 4). A large yield variation explained by environments indicated that the existence of both spatial and temporal diversity in test-environments, with large differences among environmental means causing most of the variation in grain yield. The genotypes average grain yield across environments was ranged from the lowest of $860 \mathrm{~kg} \mathrm{ha}^{-1}$ for COLL/06-1 to $3323 \mathrm{~kg} \mathrm{ha}^{-1}$ for the genotype 213-FOT-15 (Table 4). The standard cultivar ZEBRA scored the best yield of $5680 \mathrm{~kg} \mathrm{ha}^{-1}$ at the best yielding environment E7, whereas, GORBANCILION yielded the best of $685 \mathrm{~kg} \mathrm{ha}^{-1}$ at the lowest yielding environment E9 (Table 4). According to the rank of [15], genotype 213 -FOT-15 ranked first in $78 \%$ of the nine test environments. Similarly, other three better performing genotypes including 551-SEQ-1024, GORBNCILION and ZEBRA were ranked first in $67 \%$ of the test environments. However, genotypes BM-06-01, COLL/06-1 and BM-0602 were found in the lower $78-100 \%$ of the test environments (Figure 1).

\section{Result and Discussion}

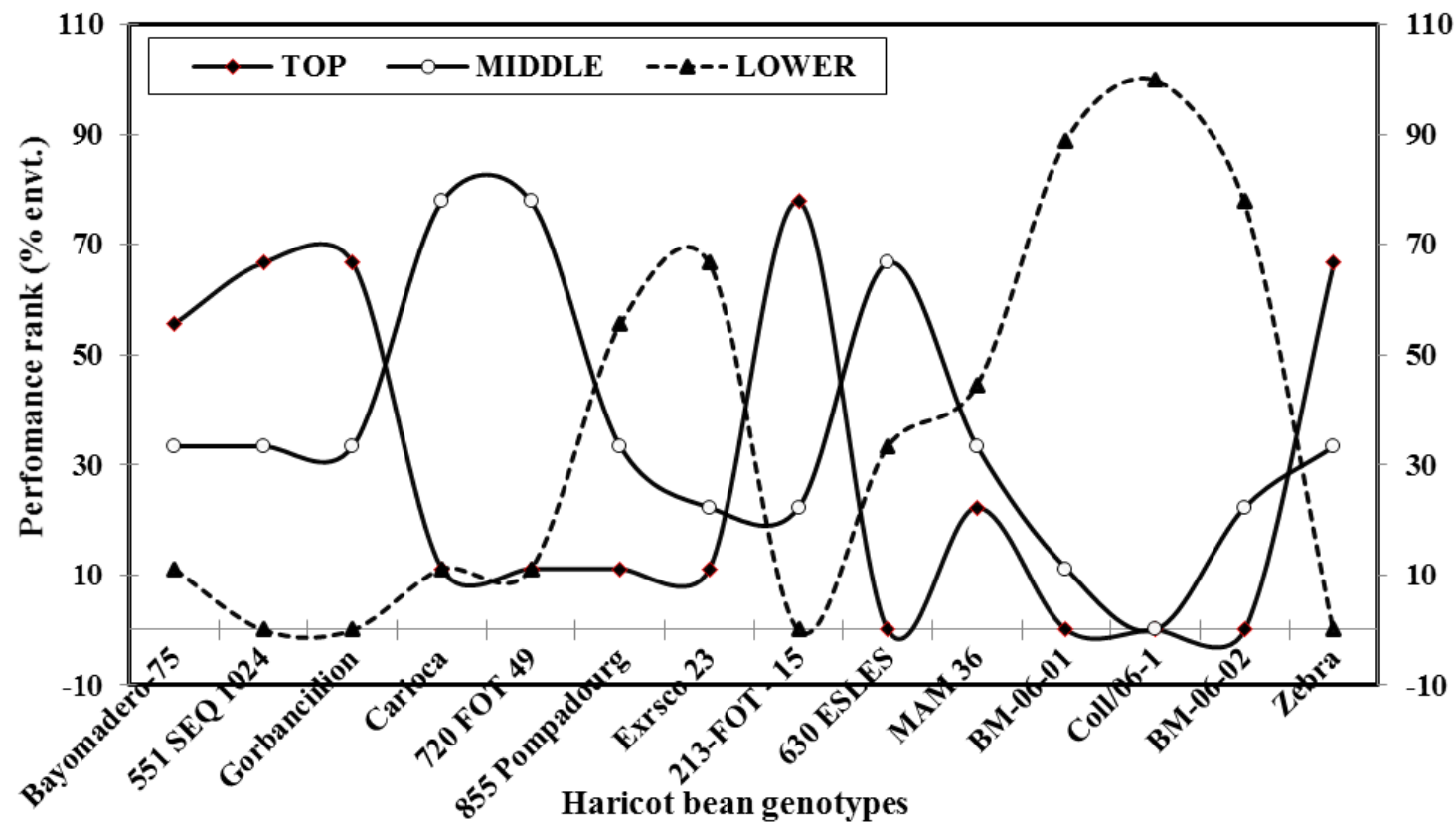

Figure 1. Performance rank (\%) of the 14 haricot bean genotypes in the "TOP, MIDDLE and LOWER" third of the test envirnments according to (Fox et al., 1990) 
Table 3. Combined analysis of variance for grain yield ( $\left.\mathrm{kg} \mathrm{ha}^{-1}\right)$ of 14 haricot bean genotypes evaluated at 9 environments of Ethiopia

\begin{tabular}{cccccc}
\hline Source of Variation & DF & Sum of squares & Mean square & F-Value & Explained \% of SS \\
\hline Environment (E) & 8 & 508464303 & 63558038 & 50.16 & $2.93^{* * *}$ \\
Bloc(Environment) & 27 & 24897182.6 & 22118 & $2.47^{* * *}$ \\
Genotype (G) & 13 & 295058368 & 1781508 & $12.74^{* * *}$ & $4.76^{* * *}$ \\
G x E & 104 & 185276857 & 373943 & 18.28 \\
Pooled error & 348 & 130132035 & \\
\hline
\end{tabular}

$\mathrm{R}^{2}=0.89$

$\mathrm{CV}(\%)=24.89$

*** is significant at 0.001 probability level; $\mathrm{DF}=$ degrees of freedom; $\mathrm{R}^{2}=$ coefficient of determination; $\mathrm{CV}=$ coefficient of variation.

Table 4. Mean performance of 14 haricot bean genotypes tested at 3 locations over 3 years

\begin{tabular}{|c|c|c|c|c|c|c|c|c|c|c|c|}
\hline & \multirow{2}{*}{ GENOTYPES } & \multicolumn{3}{|c|}{ Year-2007 } & \multicolumn{3}{|c|}{ Year-2008 } & \multicolumn{3}{|c|}{ Year-2009 } & \multirow{2}{*}{ Mean } \\
\hline & & E1 & E2 & E3 & E4 & E5 & E6 & E7 & E8 & E9 & \\
\hline 1 & BAYOMADERO-75 & $\underline{3969}$ & 4393 & 3310 & 2977 & 3209 & 999 & 5646 & 2930 & 556 & 3110 \\
\hline 2 & 551-SEQ-1024 & 3144 & $\underline{4814}$ & 3658 & 3215 & 3755 & 1770 & 4965 & $\underline{3333}$ & 504 & 3240 \\
\hline 3 & GORBANCILION & 3247 & 2959 & $\underline{4038}$ & $\underline{3512}$ & 3532 & 1776 & 5234 & 2577 & $\underline{685}$ & 3062 \\
\hline 4 & CARIOCA & 3547 & 3534 & 3514 & 2891 & 2461 & 1545 & 5023 & 1828 & 501 & 2760 \\
\hline 5 & 720 FOT-49 & 3779 & 2881 & 3330 & 3178 & 2891 & 1670 & 4924 & 2496 & 353 & 2834 \\
\hline 6 & 855 POMPADOURG & 2105 & 2345 & 3247 & 2140 & 2098 & 2256 & 4309 & 2213 & 444 & 2351 \\
\hline 7 & EXRSCO-230 & 3466 & 963 & 3571 & 772 & 609 & 1252 & 1481 & 669 & 214 & 1444 \\
\hline 8 & 213-FOT-15 & 3486 & 4212 & 2951 & 3356 & $\underline{3817}$ & $\underline{3088}$ & 5188 & 3153 & 660 & $\underline{3323}$ \\
\hline 9 & 630 ESLES & 3002 & 3946 & 1654 & 2216 & 2788 & 1227 & 4973 & 1970 & 491 & 2474 \\
\hline 10 & MAM-36 & 3692 & 3470 & 1896 & 3284 & 2543 & 964 & 4550 & 1737 & 365 & 2500 \\
\hline 11 & BM-06-01 & 2166 & 1745 & 2124 & 962 & 1046 & 1039 & 4110 & 1475 & 396 & 1674 \\
\hline 12 & COLL/06-1 & 1047 & 811 & 1444 & 725 & 1087 & 382 & 1183 & 833 & 224 & 860 \\
\hline 13 & BM-06-02 & 867 & 916 & 960 & 1574 & 1570 & 1457 & 2910 & 1907 & 247 & 1379 \\
\hline 14 & ZEBRA & 3228 & 4700 & 3895 & 3190 & 3656 & 1408 & $\underline{5680}$ & 2821 & 626 & 3245 \\
\hline & Mean & 2910 & 2978 & 2828 & 2428 & 2504 & 1488 & 4298 & 2139 & 448 & 2447 \\
\hline
\end{tabular}

Abbreviations: E1 = Kulumsa in 2007; E2 = Asassa in 2007; E3 = Dhera in 2007; E4 = Kulumsa in 2008; E5 = Asassa in 2008; E6 = Dhera in 2009; E7

= Kulumsa in 2009; E8 = Asassa in 2009 and E9 = Dhera in 2009.

\subsection{Sites Regression GGE Biplots Analysis}

The requirement of "near-perfect correlation" $(\mathrm{r}=0.95)$ between genotype IPC1 scores and genotype main effects $[8,31,33,35,36]$, which commonly occurs when genotype sum of square is $40 \%$ or more of GGE sum of squares [34] has been met in the present dataset (i.e., $r=0.994$ or genotype sum of square $=60.4 \%$ of GGE sum of squares). Therefore, the yielding ability and stability of genotypes, and discriminating ability and representativeness of the test environments can be effectively visualized using the sites regression GGE biplots. Hence, the application of GGE model for partitioning of $G \times E$ interaction revealed that the first (IPC1) and second (IPC2) multiplicative component sum of squares, with their cumulative degrees of freedom of 38, were explained $85.76 \%$ of the interaction sum of squares (Figure 2). This showed that there was a differential yield performance among the haricot bean genotypes across the nine test environments due to the presence of significant $G \times E$ interaction effects. Similar result was reported in [18] in bread wheat genotypes where the first two multiplicative interaction components of GGE were accounted for $88.97 \%$ of the G $\times \mathrm{E}$ interaction sum of squares. Since further interaction principal component axes and the residual captured mostly noise and did not help to predict validation observations, first and second multiplicative components with their largest proportion of sum of squares of $G \times E$ interaction were adequate enough to cross-validate the current haricot bean grain yield and test environment variation. The prediction assessment also indicated GGE with only first two multiplicative component axes was the best predictive model [31].

The relative position of 14 haricot bean genotypes on IPC2 vs. IPC1 GGE biplot is displayed in Figure 2. This biplot classified the genotypes into high and low yielding types, and the two productivity classes into stable and unstable performance. All genotypes that had IPC1 scores greater than zero including ZEBRA, 551-SEQ-1024, 213FOT-15, BAYOMADERO-75, 720-FOT-49, CARIOCA, GORBANCILLION, MAM-36 and 630-ESLES were found above average yielding and adaptable, while all genotypes that had negative IPC1 scores, namely EXRSCO-230, 855-POMPADOURG, BM-06-01, COLL/06-1 and BM-06-02 were found below average yielding and non-adaptable (Figure 2 and Table 4). This revealed that the sites regression GGE was $100 \%$ efficient in exhibiting the existing $\mathrm{G} \times \mathrm{E}$ interaction in the present haricot bean dataset. Similar result was reported in [39], whereas, inconsistencies in which some low yielding genotypes demonstrated greater than zero IPC1 scores and vice-versa has been reported in barley [41] and field pea [26]. According to [31], an ideal genotype is a genotype that had high mean performance across environments with high positive IPC1 value and near zero absolute value of IPC2 score. Thus, high yielding genotypes ZEBRA, BAYOMADERO-75, 551-SEQ-1024 and 213-FOT-15, with their 28.47, 24.63, 26.84 and 26.16 IPC1 values and $0.93,2.22,2.17$ and 6.89 absolute IPC2 scores, respectively (Figure 2), were found stable across test environments and considered as ideal genotypes. 


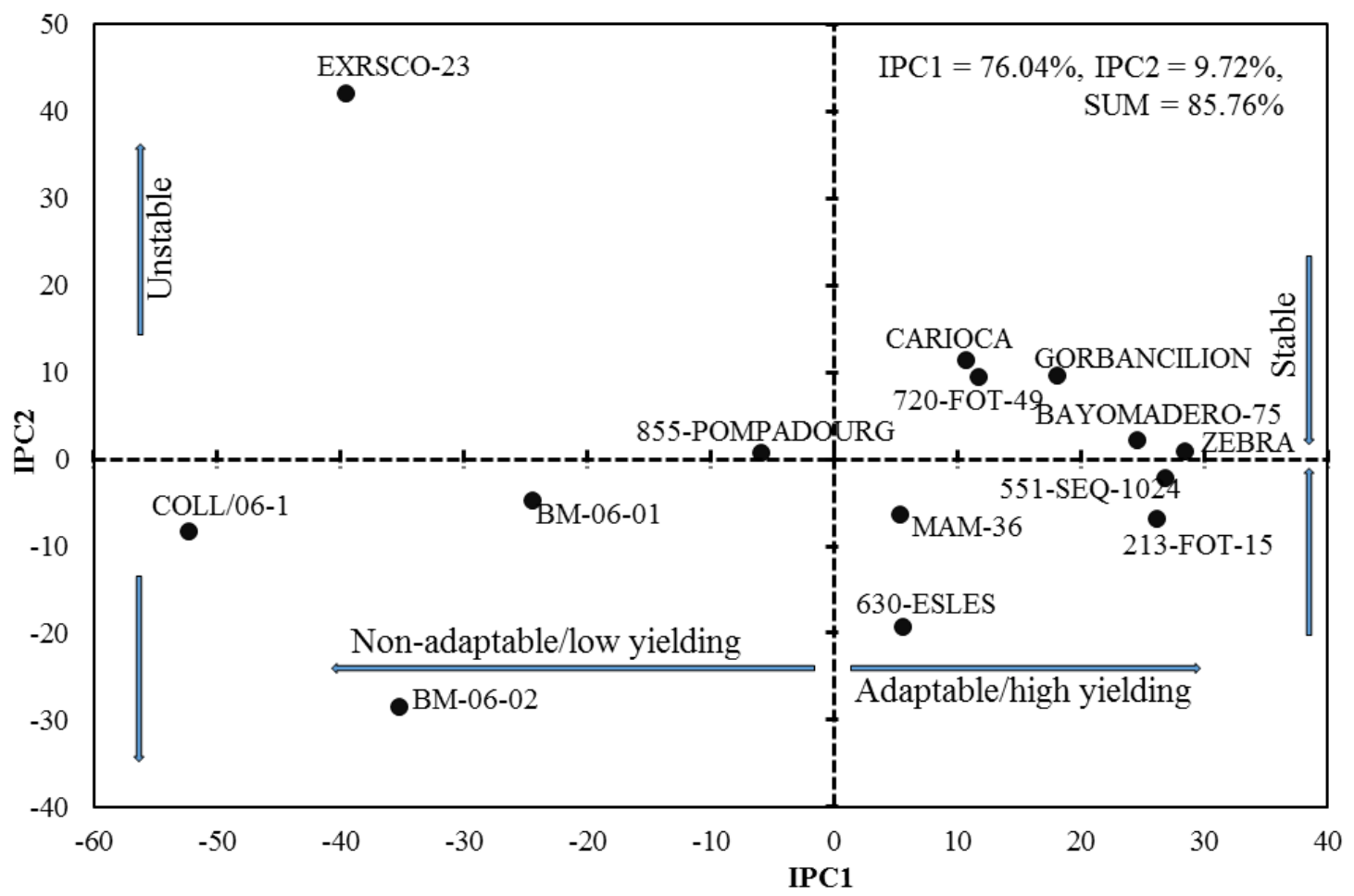

Figure 2. GGE Biplot visualizing the relative position of 14 haricot bean genotypes tested over 9 environments

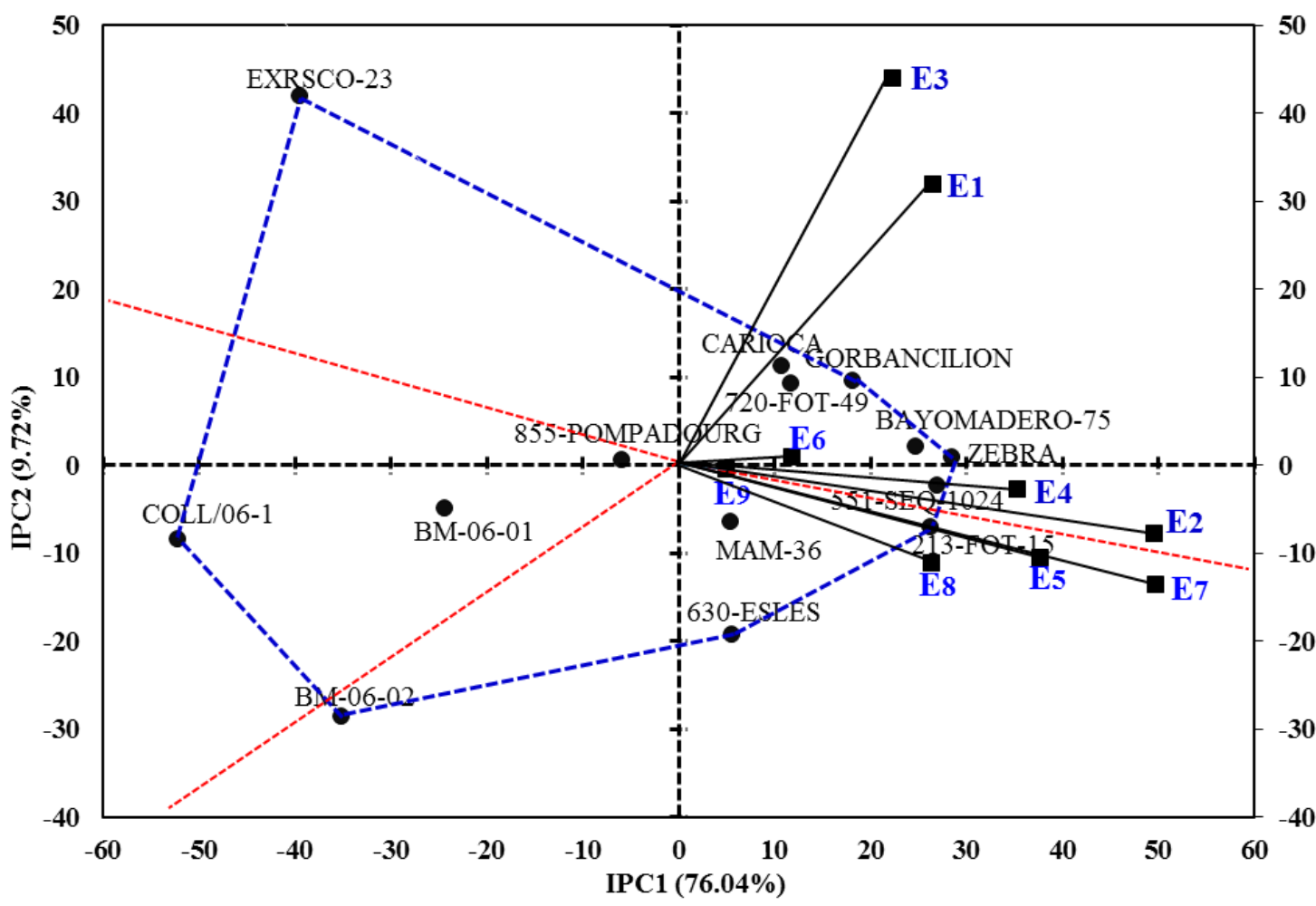

Figure 3. Genotype plus genotype $\times$ environment (GGE) biplot obtained from sites regression analysis showing the yielding ability ("which-wonwhere") of 14 haricot bean genotypes tested over 9 environments

\subsection{Mega-environment Analysis}

The "which-won-where" view of the GGE biplot, which consisted of an irregular polygon formed by connecting vertex genotypes and a set of lines drawn from the biplot origin and intersecting the sides of the polygon at right angles, was indicated in Figure 3. The vertex genotypes in this case were GORBANCILION, ZEBRA,
213-FOT-15, 630-ESLES, BM-06-02, COLL/06-1 and EXRSCO-230. Figure 3 helped to seek opportunities to sub-divide the target environment into sub-regions (megaenvironments). Thus, it classified the environment markers into two sectors (i.e., two mega-environments). This revealed that no single genotype had highest yield in all environments. Five environments including E1, E2, E3, E4 and E6 were grouped into the same mega-environment, 
whereas, the remaining four environments namely E5, E7, E8 and E9 were grouped into another mega-environment (Figure 3). None of the test locations across all years were clustered into the same sector, indicating the inconsistency in performance of genotypes over years at a given single location. On the other hand, environment IPC1 scores had all positive values leading to non cross-over type $\mathrm{G} \times \mathrm{E}$ interaction. Unlike environment IPC1, environment IPC2 scores had both negative and positive values. This indicated that there was a difference in ranking orders among genotypic yield performances across environments leading to crossover $\mathrm{G} \times \mathrm{E}$ interaction (Figure 3). This result was consistent with previous reports $[34,39,40]$.

The distances from the origin $(0,0)$ are indicative of the amount of interaction exhibited by genotypes over environments or environments over genotypes [30]. Unlike the vertex genotypes, those that were located near the biplot origin, for example 855-POMPADOURG, had demonstrated less responsive to the changing environments. According to [37], vertex genotypes, because they are farthest from the origin, they are either best or poorest in some or all test environments. Therefore, they positively or negatively expressed a highly interactive behaviour and contributed more to the exhibited $G \times E$ interaction. Thus, vertex genotypes
ZEBRA, GORBANCILION and 213-FOT-15 were found the best performer but EXRSCO-230, COLL/06-1 and BM-06-02 were the poorest across environments and manifested their high contribution to the existed $\mathrm{G} \times \mathrm{E}$ interaction. Similarly, those near origin environments, for example E6 and E9, exhibited nearly additive behavior over genotypic performance (Figure 3). This showed that genotypic yield in E6 and E9 were highly associated with over all environments mean yield, i.e., these two environments have average response to all genotypes. In contrast, E2 and E7, with their longest projection from the biplot origin, showed higher variation. This showed that performance consistency of the genotypes over seasons was better at E6 and E9 than it was at E2 and E7. Environments within the same sector of the polygon are assumed to share the same winner genotypes. Accordingly, genotypes ZEBRA, 551-SEQ-1024 and GORBANCILION were winner in mega-environments E1, E2, E3 and E4, whereas, 213-FOT-15 was a winner genotype in E5, E7 and E8 (Figure 3). Genotypes, which were not associated with any of the tester environments found poorly performed. For example, genotypes EXRSCO-230, COLL/06-1, BM-06-01 and BM-06-02 had shown their poor performance across the test environments (Figure 3; Table 4).

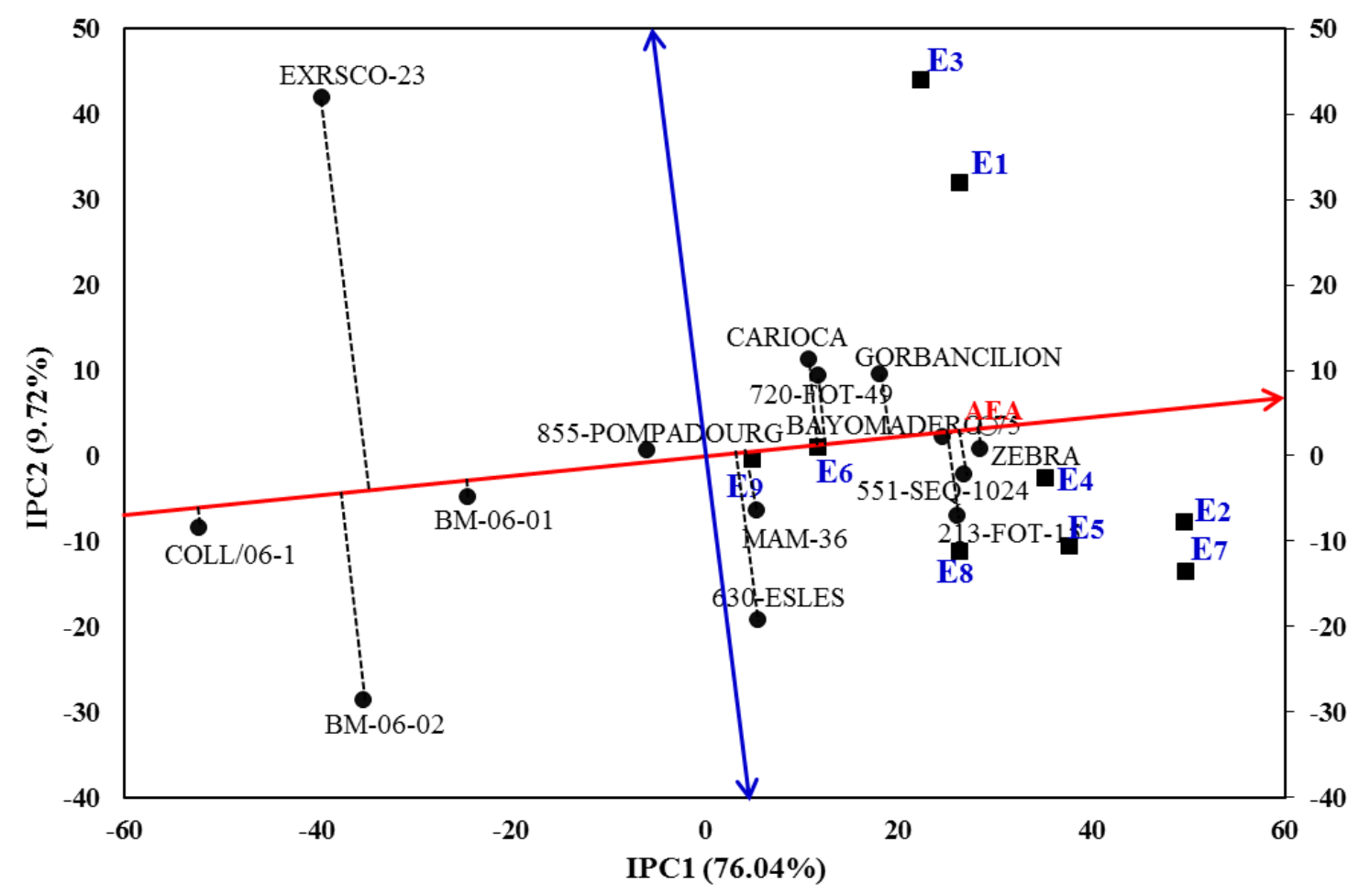

Figure 4. The average environment axis (mean-vs-stability) view of the GGE biplot obtained from the sites regression

\subsection{Genotype Evaluation}

The mean-vs-stability view of the GGE biplot (Figure 4), which is defined by the average of the first two interaction principal component scores of all test environments in the biplot, is an effective display for visual evaluation of the current haricot bean genotypes in both mean performance and stability aspects [39,40]. According to [34], superior genotype is a genotype that has both high mean performance and high stability across a mega-environment. The “average environment axis (AEA)” arrow (Figure 4) points to higher mean performance for the genotypes [40], and consequently help to rank the genotypes according to their mean performance. Thus, the current haricot bean genotypes were ranked according to their mean performance as follows: ZEBRA > 551-SEQ-1024 > 213FOT-15 = BAYOMADERO-75 > GORBANCILION > 720-FOT-49 = CARIOCA $>$ MAM-36 = 630-ESLES > "mean yield" > 855-POMPADOURG > BM-06-01 > EXRSCO-230 > BM-06-02 > COLL/06-1. This genotypic performance ranking based on AEA is nearly coincided with the mean performance of the genotypes in Table 4 . 
Such consistence in this study was occurred due to the near perfect correlation $(r=0.994)$ obtained between genotypic main effect and first interaction principal component scores.

According to [40], the double-arrowed line that passes through the biplot origin and perpendicular to the AEA helps to estimate the genotypes contribution to the exhibited $G \times E$ interaction variance, both arrows indicating to the higher performance variability or lesser stability of the genotypes in both directions. Based on this principle, genotypes BAYOMADERO-75 and 855POMPADOURG, which were located either almost on or very close to the AEA (Figure 4), were found the most stable genotypes with above and below average mean performance, respectively. This showed that the rank of these two genotypes were highly consistent across environments within their respective mega-environment. In contrast, 630-ESLES and CARIOCA, and EXRSCO230 and BM-06-02, with their longest projection onto the AEA, were the two least stable genotypes with above and below average mean performance, respectively (Figure 4).

\subsection{Test Environment Evaluation}

Test environment evaluation is important to identify locations that can be used effectively to select superior genotypes for mega-environment. The "discriminating vs. representativeness" view of the GGE biplot, which is an important measure to evaluate the test environments [10], was indicated in (Figure 5). The length of vectors of an environment from the biplot origin, which is proportional to the genotypic mean standard deviation within the respective environment, is used to measure the discriminating power of the test environments $[38,40]$. Those environments, which have longest projection from the biplot origin, for example E2, E7, E3 and E1, were found more discriminating of the genotypes. On the other hand, E9 and E6, with their shortest vector from the biplot origin, were found less discriminating of the test genotypes (Figure 5). In such an environment, all genotypes tend to perform uniformly and one can draw little or no information about the genotypic performance difference. Therefore, these environments could be considered as less important environments for selection of haricot bean genotype.

The AEA of Figure 5 is another benefit of the GGEbiplot to indicate the test-environments representativeness of the target environment. Based on [38], a test environment that has a smaller angle with the AEA is more representative of other test environments. Consequently, E4 and E2 are more representative of the other test environments whereas, E3, E1 and E8, with their wider angle from the AEA, are the least representative of the other test environments. As described by [40], an "ideal" test environment is an environment that had the ability to discriminate the genotypes and must be representative of the target environment. Hence, E2 was identified as an ideal environment that has both discriminating ability of the genotypes and representative of the other test environments. Therefore, this environment can be used to effectively select superior haricot bean genotypes that can perform consistently best across environments. For instance, genotypes ZEBRA and 213-FOT-15 were winner at E2, and found superior across all the remaining environments. On the other hand, if the testing environments sub-divided in to megaenvironments, the environment that best discriminate the genotypes but not representative of the other environments would help to select specifically adapted genotypes [38]. Therefore, E1 and E3, which has high discriminating ability of the genotypes but not representative of the other test environments (Figure 5), would be used to select specifically adapted genotypes.

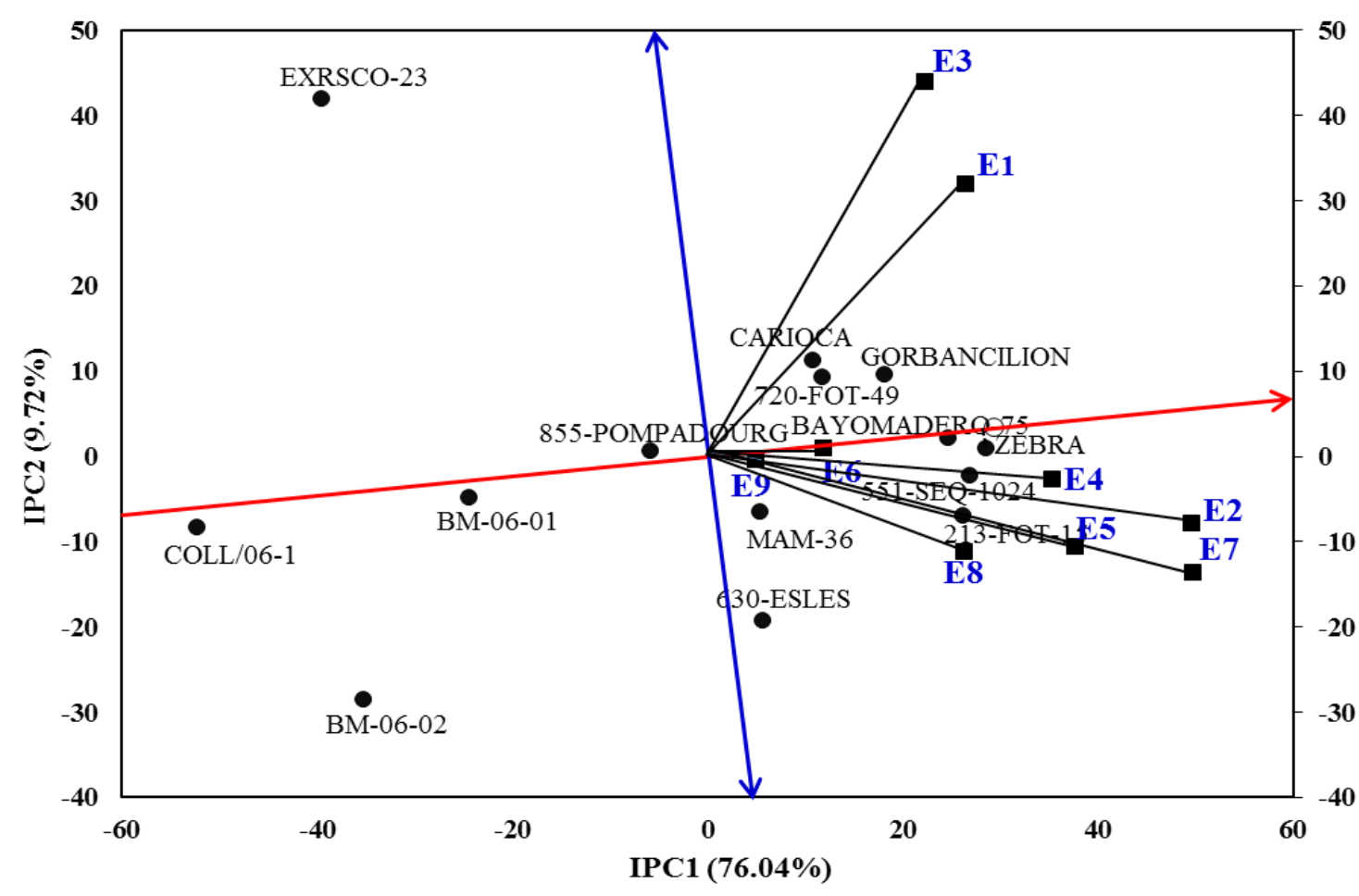

Figure 5. Discriminating ability vs. representativeness view of the GGE biplot obtained from the sites regression 


\section{Conclusion}

The present study revealed that haricot bean yield was highly influenced by variations among the growing environments followed by the differences among genotypic effects and $\mathrm{G} \times \mathrm{E}$ interaction contributed the least. This study also clearly demonstrated that the sites regression GGE biplot model was found effective for determining the magnitude and pattern of $\mathrm{G} \times \mathrm{E}$ interaction effect and visualized the yielding ability and stability of haricot bean genotypes, and discriminating ability and representativeness of the test environments. Though there were no genotypes that showed generally superior performance across all the test environments, 213-FOT-15 is ranked first in $78 \%$ of the test environments. Moreover, other three better performing genotypes including 551-SEQ-1024, GORBNCILION and ZEBRA, were ranked first in $67 \%$ of the nine test environments. Four high yielding genotypes including ZEBRA, BAYOMADERO-75, 551-SEQ-1024 and 213FOT-15, with their near-zero IPC2 and high positive IPC1 scores, were found stable across environments and considered ideal. Vertex genotypes including GORBANCILION, ZEBRA, 213-FOT-15 and 630ESLES, were identified as winner genotypes for different mega-environments. Besides, E2, E7, E3 and E1, with their longest projection from the biplot origin, were among the test environments that most discriminated the genotypes. On the other hand, two environments, namely E9 and E6, are found least discriminating of the test genotypes, i.e., exhibited average response to all genotypes.

\section{Acknowledgements}

The authors would like to thank staff members of Legumes Breeding and Genetics Research Division of Kulumsa Agricultural Research Center, Ethiopia for their unreserved efforts in trail management and data collection.

\section{Statement of Competing Interests}

The authors have no competing interests.

\section{References}

[1] Abeya, T., Chemeda, D., Girma, M., Dagnachew, L., Negash, G. "Regression and additive main effect and multiple interactions (AMMI) in common beans (Phaseolus vulgaris L.) genotypes," Ethiopian Journal of Biological Science 7(1), 45-53, (2008).

[2] Allard, R.W., Bradshaw, A.D., "Implication of genotypeenvironmental interaction in applied plant breeding," Crop Science 5, 503-506, (1964).

[3] Asfaw, A., Alemayehu, F., Gurmu, F., Atnaf. M., “AMMI and SREG GGE biplot analysis for matching varieties onto soybean production environments in Ethiopia," Scientific Research and Essays, 4(11), 1322-1330, (2009).

[4] Burgueno, J., Crossa, J., Vargas, M., "SAS Programs for graphing GE and GGE biplots,” CIMMYT, INT. Mexico, (2001). Available: http://www.cimmyt.org/biometrics/biplots.exe. [Accessed Sep., 2012].

[5] Ceccarelli, S., "Wide adaptation: How wide?” Euphytica 40, 197205, (1989).
[6] Central Statistical Authority (CSA), "Federal democratic republic of Ethiopia, agricultural samples survey, Report on area and production of major crops 3, 2013, p251.

[7] Crossa, J., "Statistical analysis of multi-location trials," Advances in Agronomy, 44, 55-85, (1990).

[8] Crossa, J, Cornelius, P.L., Yan, W., "Biplots linear-bilinear model for studying cross over genotype x environment interaction," Crop Science, 42(2), 619-633, (2002).

[9] Dawit, T., Wuletaw, T., Muluken, B., "Genotype x environment interactions and grain yield stability of haricot bean varieties in Northwest Ethiopia,” Scientific Research and Essays, 7(41), 34873493, (2012).

[10] Dehghani, H., Ebadi, A., Yousefi, A., "Biplot analysis of genotype $\mathrm{x}$ environment interaction for barley yield in Iran,” Agronomy Journal, 98, 388-398, (2006).

[11] Ethiopian Mapping Authority (EMA), National Atlas of Ethiopia, Ethiopian Mapping Authority, Addis Ababa, (1988).

[12] Falconer, R.D., Mackay, Trudy F.C., Introduction to quantitative genetics, (4 ${ }^{\text {th }}$ Ed). Longman, Group limited, Malaysia, (1996).

[13] Ferreira, D.F., Demetrio, C.G.B., Manly, B.F.J., Machado, A.A., Vencovsky, R., "Statistical model in agriculture: biometrical methods for evaluating phenotypic stability in plant breeding," Cerne Lavras, 12 (4), 373-388, (2006).

[14] Flores, F., Moreno, M.T., Cubero, J.J., "A comparison of univariate and multivariate methods to analyze G x E interaction," Field Crops Research, 56, 271-286, (1998).

[15] Fox, P.N., Skovm, B., Thompson, B.K., Braun, H.J., Cormier, R., "Yield and adaptation of hexaploid spring triticale," Euphytica, 47, 57-64, (1990).

[16] Gauch, H.G., "Statistical analysis of yield trials by AMMI and GGE,” Crop Science, 46, 1488-1500, (2006).

[17] Hernandez, M.V., Crossa, J., "The AMMI analysis and graphing the biplot,” CIMMYT, INT. Mexico, (2000). Available: http://www.cimmyt.org/biometrics/biplots.exe. [Accessed, Sep., 2012].

[18] Hintsa, G.H., Fetien, A., “AMMI and GGE Biplot analysis of bread wheat genotypes in the Northern part of Ethiopia,” Journal of Plant Breeding and Genetics, 1, 12-18, (2013).

[19] Hussein, M.A., Bjornstad, A., Aastveit, A.H., "SAS G X E STAB: A SAS Program for Computing Genotype $X$ Environment Stability Statistics,” Agronomy Journal, 92(3), 454-459, (2000).

[20] Navabi, A., Yang, R.C., Helm, J., Spawer, D.M., "Can spring wheat growing mega-environments in the northern great plain be dissected for representative locations or niche-adapted genotypes?” Crop Science, 46, 1107-1116, (2006).

[21] Piepho, H.P., "Methods for comparing the yield stability of cropping systems - a review," Journal of Agronomy and Crop Science, 180, 193-213, (1998).

[22] Reza M., Armon, M., Shabani, A., Daryaei, A., "Identification of Stability and Adaptability in Advanced Durum Genotypes Using AMMI Analysis,” Asian Journal of Plant Science, 6(8), 12611268, (2007).

[23] Samonte, S.C.P.B., Wilson, L.T., McClung, A.M., Medley, J.C., "Targeting cultivars onto rice growing environments using AMMI and SREG GGE biplot analysis,” Crop Science, 45, 2414-2424, (2005).

[24] SAS., System Analysis Software. Version 9.0. SAS Institute Inc., Cary, North Carolina, USA, 2002.

[25] Setegn, G., Habtu, A., "Genotype x environment interaction and stability analysis of seed yield in navy bean genotypes," African Crop Science Journal, 11(1), 1-7, (2003.

[26] Tolessa, T.T., Keneni, G., Sefera, T., Jarso, M., Bekele, Y., "Genotype x Environment Interaction and Performance Stability for Grain Yield in Field Pea (Pisum sativum L.) Genotypes,” International Journal of Plant Breeding, 7(2), 116-123, (2013).

[27] Teshale, A., Habtu, A., Paul, K., "Development of improved Haricot bean germplasm for the mid- and low- altitude sub-humid agro-ecologies of Ethiopia,” In: Kemal Ali, Gemechu, K., Seid, A Malhotra, R., Beniwal, S., Makkouk, K., Halila, M.H. (eds.). Food and forage Legumes of Ethiopian: Progress and prospects. Proceedings of a workshop on food and forage Legumes, Addis Ababa, Ethiopia. ICARDA, Aleppo, Syria, 87-94, (2006).

[28] Tsedeke, A., Arega, D.A., David, B., Bekele, Sh., Said, S., Alastair, O., Solomon, A., "Tropical Grain Legumes in Africa and South Asia, Knowledge and Opportunities,” Tropical Legume II Project Research Report 1, p116, (2011).

[29] Van Eeubwijk, F.A., Denis, J.B., Kang, M.S., "Incorporate Additional Information on Genotypes and Environments in 
Models for Two-way Genotype-by-Environment Tables," In: Kang, M.S., Gauch, H.G. (eds.), Genotype-by-Environment Interaction, CRC Press, Boca Raton, FL, 15-49, (1996).

[30] Voltas, J., Van, E.F., Igartua, E., García, del., Moral, L.F., MolinaCano, J.L., Romagosa, I., "Genotype by environment interaction and adaptation in barley breeding: Basic concepts and methods of analysis,” In: Slafer, G.A., Molina-Cano, J.L., Savin, R., Araus, J.L., Romagosa, I. (eds.) Barley Science: Recent Advances from Molecular Biology to Agronomy of Yield and Quality, The Harworth Press Inc., New York, 205-241, (2002).

[31] Yan, W., Hunt, L.A., Sheng, Q., Szlavnics, Z., "Cultivar evaluation and mega-environment investigation based on GGE biplot,” Crop Science, 40, 597-605, (2000).

[32] Yan, W., "GGE Biplot: A Windows application for graphical analysis of multi-environment trial data and other types of twoway data,” Agronomy Journal, 93, 1111-1118, (2001).

[33] Yan, W., Hunt, L.A., "Interpretation of genotype x environment interaction for winter wheat yield in Ontario,” Crop Science, 41, 19-25, (2001).

[34] Yan, W., Cornelius, P.L., Crossa, J., Hunt, L.A., “Two types of GGE Biplots for analyzing multi-environment trail data," Crop Science, 41, 656-663, (2001)
[35] Yan, W., "Singular value partitioning in biplot analysis of multienvironment trial data,” Agronomy Journal, 94, 990-996, (2002).

[36] Yan, W., Rajcan, I., "Biplots analysis of the test sites and trait relations of soybean in Ontario," Crop Science, 42, 11-20, (2002).

[37] Yan, W., Kang, M.S., GGE Biplot Analysis: A Graphical Tool for Breeders, Geneticists and Agronomists, ( $1^{\text {st }}$ Edn), CRC Press LLC, Boca Roton, Florida, (2003)

[38] Yan, W., Tinker, N.A., "Biplot analysis of multi-environment trial data: Principles and applications," Canadian Journal of Plant Science, 86, 623-645, (2006).

[39] Yan, W., Kang, M.S., Ma, B., Wood, S., Cornelius, P.L., "GGE biplot vs. AMMI analysis of genotype-by-environment data," Crop Science, 47, 643-655, (2007).

[40] Yan, W, "GGE Biplot vs. AMMI Graphs for Genotype-byEnvironment Data Analysis,” Journal of Indian Society Agricultural Statistics, 65(2), 181-193, (2011).

[41] Zerihun, J., “GGE-biplot Analysis of Multi-environment Yield Trials of Barley (Hordeum vulgare L.) Genotypes in Southeastern Ethiopia Highlands," International Journal of Plant Breeding Genetics, 5(1), 59-75, (2011).

[42] Zobel, R.W., Wright, M.S., Gauch, H.G., "Statistical analysis of a yield trial,” Agronomy Journal, 80, 388-393, (1988). 